\title{
Multistakeholder Perspectives on Data Sharing to Address Patient Food Insecurity
}

\author{
Andrea Lynn Nederveld, MD, MPH, Jodi Holtrop, PhD, MCHES, \\ Kelsey Fife Duarte, MPH, CHES, Macharnie Skalecki, and \\ Elena T. Broaddus-Shea, PhD
}

Background: Social determinants of health (SDOH) influence health outcomes. Food insecurity (FI) is the most common need related to SDOH. Many primary care practices and health systems have begun to screen for FI and refer patients to resources. How this process is viewed by multiple stakeholders, including patients, health care workers, and staff at food assistance organizations (FAOs), will influence its impact.

Methods: In this mixed-methods study, we completed 42 interviews with individuals from the 3 stakeholder groups. We then conducted a survey with 126 respondents using questions developed from the qualitative results.

Results: All stakeholders recognized the impact FI has on health outcomes, but perspectives varied on the value of sharing information through referrals to FAOs and concerning receipt of services, including privacy concerns and that the process would require significant work and not necessarily improve FI.

Discussion: Stakeholders agree that FI impacts health but have differences in perceptions around screening and referral done in health care settings. Perspectives of multiple stakeholders need to be considered when designing these systems.

Conclusion: Successfully designing systems to address FI through referral to FAOs requires input of multiple stakeholders because perspectives on the value and work required for this process vary. (J Am Board Fam Med 2022;35:85-95.)

Keywords: Colorado, Community Medicine, Data Sharing, Food Insecurity, Primary Health Care, Qualitative Research, Referral, Social Determinants of Health, Surveys and Questionnaires

\section{Background}

In 2014, the Institute of Medicine recommended that health care settings begin to screen for and report on social determinants of health (SDOH)related needs, ${ }^{1}$ leading to development of screening tools and increasing implementation of screening

This article was externally peer reviewed.

Submitted 2 March 2021; revised 24 August 2021; accepted 9 September 2021.

From University of Colorado School of Medicine Department of Family Medicine (AN, JH, KFD, MS, ETB-S).

Funding: This research was supported by the Colorado Evaluation and Action Lab of the University of Denver. The opinions expressed are those of the authors and do not represent the views of the Colorado Lab or the University of Denver.

Conflict of interest: none.

Corresponding author: Andrea Lynn Nederveld, MD, MPH, University of Colorado at Denver-Anschutz Medical Campus, Grand Junction, 1635 Aurora Ct, Aurora, CO 80045 (E-mail: andrea.nederveld@cuanschutz.edu). processes. ${ }^{2-5}$ However, even earlier, the American Academy of Pediatrics and others recommended screening for food insecurity (FI) in health care settings. ${ }^{6,7}$ FI is defined by the U.S. Department of Agriculture as "a household level economic and social condition of limited or uncertain access to adequate food." ${ }^{8} \mathrm{FI}$ is the most commonly identified need related to SDOH, affecting approximately $11 \%$ of the population in the United States in 2019 and up to $23 \%$ after the onset of the COVID-19 pandemic in March 2021. ${ }^{9,10}$

Patients identified as experiencing FI may benefit from being connected to resources, but several barriers exist, including time needed, lack of patient trust and comfort with the process, and the multiple points where referrals to food assistance organizations (FAOs) can fail (eg, lack of communication between the patient and FAO, 
ineligibility for services). ${ }^{11}$ In addition, closedloop communication, where practices receive information about receipt of services, may help health care providers know that patient needs are being met. Effective systems for making referrals to FAOs allowing this kind of closed-loop communication with practices rarely exist or are in early stages of development. ${ }^{12-15}$

Each of these screening, referral, and closedloop communication processes involve personal data sharing. In addition, attitudes toward data sharing and privacy differ across population groups. ${ }^{16-19}$ Although existing literature indicates high acceptability of data sharing among patients and caregivers for the purposes of addressing FI in urban and pediatric settings, less is known about perspectives in the context of adult primary care and in nonurban areas. ${ }^{20-22}$ In addition, this type of data sharing depends on the comfort and participation of 3 primary stakeholder groups: patients, health care workers (HCWs), and FAO staff. Information on the perspectives of all 3 of these stakeholder groups is scarce, and yet the active involvement of each is essential for successful interventions to address FI in health care settings. ${ }^{23}$ In this article, we share findings regarding multistakeholder perspectives on data sharing for the purposes of FI screening and referral in primary care settings located in rural and smaller town locations.

\section{Methods}

We used an exploratory sequential mixed-methods design, beginning with semistructured interviews, followed by a survey. ${ }^{24}$ Data collection took place between April 2019 and March 2020. The Colorado Multiple Institutional Review Board approved our protocol, and we used the Consolidated Criteria for Reporting Qualitative Research as a guide for reporting our results. ${ }^{25}$ We conceptualized the process of addressing FI in health care settings as having 3 distinct steps: screening to identify FI, referral to FAOs, and closing the loop. Figure 1 describes each step and the corresponding flow of data among the 3 key stakeholder groups: patients, HCWs and FAOs.

This research took place in Mesa County, Colorado, which has 1 medium-sized city, Grand Junction, with a population of 63,500 , and a total county population of $154,000,{ }^{26}$ indicating that a majority of Mesa County residents live in small towns or rural areas. Eleven percent of Mesa County residents live in poverty, compared with $9.3 \%$ statewide, $^{26}$ and $12.6 \%$ reported FI before the COVID-19 pandemic began. ${ }^{27}$ The Latinx community is the largest minority group, comprising $15 \%$ of the population. ${ }^{26}$

\section{Qualitative Data Collection and Analysis}

FI participants (ie, patients) were recruited by: (1) care managers (generally social workers or medical assistants with added experience and training) at 2 practices during scheduled visits or (2) the research team at community events. Prospective participants were asked screening questions to confirm lifetime experience of FI. ${ }^{6}$ We also recruited providers and care managers at 5 practices and staff at 12 FAOs.

Members of the research team (EB, AN, or MS, all non-Hispanic females with training in qualitative interviewing; MS with college-level training in Spanish) conducted interviews either in-person or by phone in English or Spanish, depending on the participant's preferred language. Research team members did not have existing relationships with any of the respondents. Informed consent was obtained before all interviews. We developed and used a separate semistructured interview guide for each stakeholder group. Questions were based on a list of constructs developed with the assistance of the project advisory group, a committee of individuals with professional or lived experience with FI. We pilot tested each guide with 2 people from the specific stakeholder group and revised it accordingly. Interviews lasted 30 minutes on average

Figure 1. Steps and data flow for screening and referral. Abbreviations: WIC, Women, Infants, and Children; SNAP, Supplemental Nutrition Assistance Program.

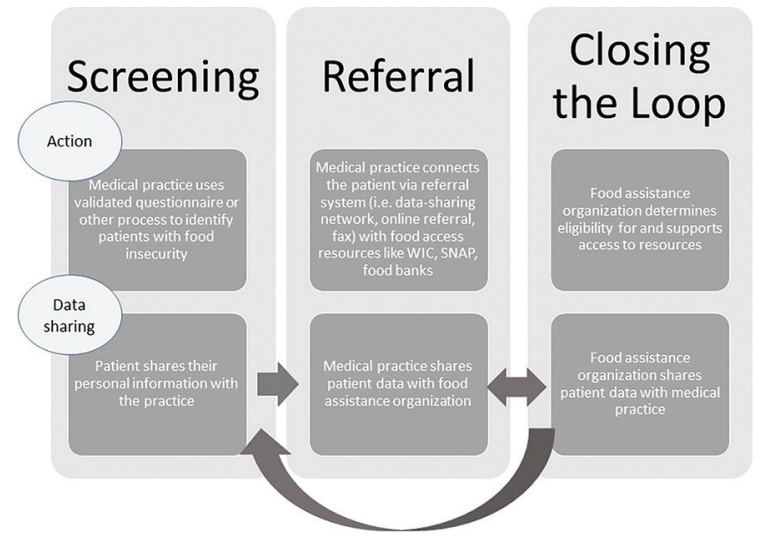


(range 15 to 65 minutes) and were audio recorded and professionally transcribed. Spanish-language interviews were transcribed in Spanish and then translated to English. Participants received a \$25 gift card.

Rapid qualitative analysis techniques have been shown to result in similar theme development when compared with traditional qualitative thematic analysis, offer earlier return of findings, and are often combined with other analytic methods. ${ }^{28,29}$ These approaches work well for studies in which specific answers are sought for intervention development or refinement, such as with this study. We therefore analyzed interview data using a 2-step process consisting of a modified rapid analysis approach $^{30,31}$ followed by coding to identify emergent themes. We first developed an interview summary template that captured respondents' comments regarding the 3 steps in screening and referral outlined previously. After each interview, the interviewer immediately completed the template. A second research team member then read each transcript and reviewed the summary to ensure accuracy. We then developed a matrix with columns depicting categories from the summary template and rows depicting individual respondents. The content from each individual summary was directly abstracted into this matrix, allowing the research team to review the summarized statements of all respondents for each category, and thereby to begin identifying themes and variation across respondents.

Following the rapid analysis, we developed a simple code list based on topics emerging as salient for further exploration. These included, eg, "experiences with screening and referral" and "perspectives on data-sharing." Given that the coding was in larger conceptual chunks, coding across reviewers was highly consistent. As an additional measure, 2 researchers (AN and $\mathrm{EB}$ ) coded independently and compared results for 2 transcripts and found high consistency of code use, thus not requiring further double-coding. ${ }^{32}$ AN and EB then coded all transcripts independently using ATLAS.ti software (version 8.0, Scientific Software Development GmbH, Berlin, Germany). Three study team members (AN, EB, and $\mathrm{JH}$ ) then reviewed all coded segments and through an iterative process of group discussion identified key themes specific to each stakeholder type and each process step.

\section{Quantitative Data Collection and Analysis}

With input from our project advisory committee, we developed a survey examining emergent topics of interest following our qualitative analysis. Our purpose was to build from the interview data and gather confirming or disconfirming data from a larger sample of stakeholders. For example, our interview data suggested differences across stakeholder groups in perceptions of patient comfort with data sharing and helpfulness of data sharing. We therefore developed questions examining each of these domains (perceived patient comfort and perceived helpfulness) in relation to each of the 3 steps from our conceptual model (see Figure 1). After pilot testing, we administered the same survey to individuals from all 3 stakeholder groups, to allow for comparison of responses across groups.

Researchers (MS or EB) recruited patients to participate in the survey in the waiting rooms of 3 clinics, displaying recruitment signs and waiting for patients to approach. Prospective participants were screened to confirm lifetime experience of FI. ${ }^{6}$ After obtaining informed consent, surveys were completed in person in a private space. $\mathrm{HCW}$ s and FAO staff received e-mails requesting participation and completed surveys using the online survey platform REDcap. Participants received a \$10 gift card. Survey data were descriptively analyzed by calculating response frequencies, disaggregated by stakeholder type.

Following data collection and analysis, member checking was done through 6 presentations of results and discussions with $\mathrm{HCW}$, FAO staff, academic experts on FI, and patients.

\section{Results}

We interviewed 42 individuals: 20 patients, $12 \mathrm{FAO}$ staff members, and $10 \mathrm{HCWs}$ (5 physicians, 5 care managers/staff who complete screenings for SDOH). We surveyed a total of 126 individuals: 50 patients (representing an $83 \%$ response rate), 37 FAO staff (representing a $63 \%$ response rate), and $39 \mathrm{HCWs}$ (for the survey, only physicians and advanced practice providers were asked to respond, a $76 \%$ response rate). Providers represented 5 primary care practices ( 1 federally qualified health center, 1 residency program serving a low-income population, 1 large multisite private practice, and 2 small private practices). The 49 FAO staff represented 16 organizations (5 governmental, 11 
community-based organizations). As providers and FAO staff who had participated in interviews also received an invitation to participate in the survey, there was some overlap in those groups but no overlap in the patient participants. Respondent demographic characteristics and responses to FI questions are shown in Table 1. Of note, patients had the most lifetime personal experience with FI, although a significant number of FAO staff had also personally experienced FI. HCWs were the least likely to have personal experience of FI.

Table 1. Interview and Survey Participant Demographics

\begin{tabular}{|c|c|c|c|}
\hline & Patients & $\mathrm{HCWs}^{*}$ & FAO Staff \\
\hline \multicolumn{4}{|l|}{ Interview Participants } \\
\hline Total & 20 & 10 & 12 \\
\hline \multicolumn{4}{|l|}{ Gender } \\
\hline Male & 3 & 1 & 1 \\
\hline Female & 17 & 9 & 11 \\
\hline \multicolumn{4}{|l|}{ Age } \\
\hline 20 to 39 & 13 & 3 & 5 \\
\hline 40 to 59 & 3 & 6 & 5 \\
\hline 60 to 79 & 4 & 1 & 2 \\
\hline \multicolumn{4}{|l|}{ Race/ethnicity } \\
\hline White/Caucasian & 13 & 9 & 10 \\
\hline Latinx/Hispanic & 5 & 0 & 1 \\
\hline Multiple races/ethnicities & 2 & 1 & 1 \\
\hline \multicolumn{4}{|l|}{ Language } \\
\hline Interview conducted in English & 17 & 10 & 12 \\
\hline Interview conducted in Spanish & 3 & 0 & 0 \\
\hline \multicolumn{4}{|l|}{ Survey Participants } \\
\hline Total & 50 & 39 & 37 \\
\hline \multicolumn{4}{|l|}{ Gender } \\
\hline Male & $22(44.0 \%)$ & $14(35.9 \%)$ & $3(8.1 \%)$ \\
\hline Female & $28(56.0 \%)$ & $25(64.1 \%)$ & $34(91.9 \%)$ \\
\hline \multicolumn{4}{|l|}{ Age } \\
\hline 20 to 39 & $14(28.0 \%)$ & $15(38.5 \%)$ & $13(35.1 \%)$ \\
\hline 40 to 59 & $26(52.0 \%)$ & $19(48.7 \%)$ & $14(37.8 \%)$ \\
\hline 60 to 89 & $10(20.0 \%)$ & $5(12.8 \%)$ & $10(27.0 \%)$ \\
\hline \multicolumn{4}{|l|}{ Race/ethnicity $^{\dagger}$} \\
\hline White & $38(76.0 \%)$ & $32(82.1 \%)$ & $29(78.4 \%)$ \\
\hline Latinx/Hispanic & $9(18.0 \%)$ & $3(7.7 \%)$ & $7(18.9 \%)$ \\
\hline American Indian or Native American & $4(8.0 \%)$ & $0(0.0 \%)$ & $1(2.7 \%)$ \\
\hline Asian or Asian American & $0(0.0 \%)$ & $2(5.1 \%)$ & $0(0.0 \%)$ \\
\hline Other race or ethnicity & $2(4.0 \%)$ & $2(5.2 \%)$ & $1(2.7 \%)$ \\
\hline Prefer not to say & $0(0.0 \%)$ & $1(2.6 \%)$ & $1(2.7 \%)$ \\
\hline \multicolumn{4}{|l|}{ Language } \\
\hline Survey administered in English & $45(90.0 \%)$ & $39(100.0 \%)$ & $37(100.0 \%)$ \\
\hline Survey administered in Spanish & $5(10.0 \%)$ & $0(0.0 \%)$ & $0(0.0 \%)$ \\
\hline \multicolumn{4}{|l|}{ Food insecurity status ${ }^{\ddagger}$} \\
\hline Never food insecure & $1(2.0 \%)$ & $28(71.8 \%)$ & $14(37.8 \%)$ \\
\hline Previously food insecure & $12(24.0 \%)$ & $9(23.1 \%)$ & $13(35.1 \%)$ \\
\hline Currently food insecure & $37(74.0 \%)$ & $2(5.1 \%)$ & $10(27.0 \%)$ \\
\hline
\end{tabular}

HCWs, health care workers, FAO, food assistance organizations.

*Interview respondents included both medical providers and other medical practice staff whereas survey respondents included only medical providers.

${ }^{\dagger}$ Sums to more than $100 \%$; respondents selected all race/ethnicity categories with which they identified.

${ }^{\ddagger}$ Assessed using the Hunger Vital Sign screening tool. 
Qualitative themes and survey results: Table 2 presents our interview findings and Figure 2 presents our survey findings.

\section{Screening}

\section{Qualitative Themes}

Overall, respondents understood the connection between FI and health and believed that the data sharing involved in screening for FI was important and could give HCWs insight into patients' lives and health. Differences by stakeholder group are described below.

\section{Patients}

While respondents indicated surprise at the thought of being asked at an appointment whether they had enough food, they also indicated that they would be comfortable talking about FI. They thought knowing about FI would help their medical provider to better understand their health and ability to follow through on dietary recommendations. In contrast, a few indicated that they would not want to talk to their doctor about FI, due to wanting privacy or being concerned, eg, that Child Protective Services (CPS) would be notified if the family did not have enough food. Respondents generally felt that being asked about FI so clinic staff could suggest resources would be acceptable, but being asked for the sole purpose of data collection would not be.

\section{HCWs}

HCWs identified the value of screening for FI and indicated that screening all patients would generate helpful information but noted challenges related to staff time and logistics. Care managers in particular indicated that they thought screening questions were best asked in person and that results may not be reliable in the absence of a trusting relationship. Medical providers also expressed concern that the information gathered might not be used to actually assist patients experiencing FI.

\section{FAO Staff}

FAO staff also believed FI was related to health outcomes and that screening in health care settings could be valuable because providers could encourage people to pursue assistance. However, they were less convinced than the other 2 groups that patients would be comfortable sharing information about FI with their health care providers.
Survey Results

Eighty-two percent of patients answered that screening for FI in health care settings was "very helpful," but only $34 \%$ thought people would be "very comfortable" discussing FI. Only 59\% of HCWs answered that screening was very helpful, and $23 \%$ thought patients would be very comfortable. FAO staff seemed least favorable to this step, with $65 \%$ responding that this step would be very helpful but only $14 \%$ answering that patients would be very comfortable (see Figure 2).

\section{Referring Patients to Resources}

\section{Qualitative Themes}

Compared with screening, this step elicited more concerns from all groups, primarily around the work and logistics required to ensure effectiveness.

\section{Patients}

Patients were generally comfortable with information being shared with organizations, if the intent was connection with resources, but were emphatic that they would want to be asked permission before information was shared. Patients also reported that referral is only 1 step in accessing resources and that many other barriers exist, such as needs around transportation or inability to complete forms or take time off from work to access resources.

\section{HCWS}

Providers had privacy concerns related to the Health Insurance Portability and Accountability Act (HIPAA) about sharing patient information with FAOs. However, care managers generally said that they already shared patient contact information with programs like SNAP or WIC, indicating that some information sharing is already happening. Many reported that the work to refer is not compensated, and practices are already overwhelmed. Care managers mentioned that having improved mechanisms or formal systems for connecting patients with resources would help with logistics (eg, electronic referral systems).

\section{FAO Staff}

Collaboration with medical providers and strategies to help address FI were viewed as beneficial. However, FAO staff expressed concern that they would be unable to handle a large influx of referrals 
Table 2. Themes, Perspectives across Stakeholder Groups, and Illustrative Quotations for Qualitative Findings on Screening, Referral, and Closing the Loop to Address Food Insecurity (FI) in Primary Care Practice

\begin{tabular}{lcc}
\hline Themes & Stakeholder Perspectives* & Illustrative Quotations \\
\hline
\end{tabular}

Findings on Screening

Recognition that FI affects health

Comfort with screening and its implementation in primary care

Importance of using screening information to help people

Recognition of value if confidentiality is ensured

Concerns about workload and capacity

Barriers to accessing resources
Patients: Sometimes surprised to be asked the screening questions, but understand the health connection

HCWs: Believe it's important to understand social situation and needs

FAO staff: Believe that FI affects health and understand the connection

Patients: Generally comfortable discussing FI but some concerns about potential consequences of screening

HCWs: Unsure how to fit screening approaches that patients are comfortable with into busy clinic workflow

FAO staff: Concern that patients will not feel comfortable discussing FI

Findings on Referral

Patients: Want to know that the purpose of data collection is to suggest resources

HCWs: Concern that data collected may not be used

Patients: Generally recognize benefits but request for permission and confidentiality are necessities

HCWs: Concern about the Health Insurance Portability and Accountability Act (HIPAA), although some data sharing already happeningFAO staff: Generally recognize benefits

HCWs: Concerns about lack of staff time and lack of compensation for referral work

FAO staff: Concerns about time and capacity to respond to referrals

Patients: Encounter challenges accessing resources even if they are referred

FAO staff: Many factors can deter access, even when people are referred
[Screening] is more of a bealth check than a food check. - patient, \# $1^{\dagger}$

If [patients] can't access meals in a way that corresponds with their bealth care needs, we have to figure something out. It's. . an integral part of what primary care physicians should do. - HCW, \#25

Housing and food are basics. [Our organization] I believe belps families be bealthy and to make good decisions. -FAO staff, \#32

[The questions] made me feel kinda uncomfortable because I have had past experience with, like CPS. . .I just don't want. . a reason for them to take my daughter away. -patient, \#4

There's a lot of other things to talk about during the visit, and [there's] just not the time to identify social determinants. $-\mathrm{HCW}, \# 23$

People believe that they should rely on each other, their family, versus coming in and asking for belp. We sometimes call it the Western mentality and pride comes into play when it comes to food insecurity, too. -FAO staff, \#34

I [would feel comfortable with the screening] if it were related to the services that we were getting that day. But if it was just kind of off the fly, I would kind of question their motives. - patient, \#13

There's lots of good intentions, but putting something in a database in a computer I don't think actually belps people. $-\mathrm{HCW}$, \#28

I think I'd feel fairly comfortable as long as they keep their confidentiality. - patient, \#4

I think the main issue is that there isn't some type of a patient privacy or HIPAA violation with sharing that information to try and connect them with the resources $-H C W$, \#26

Physicians are overloaded with information right now. . so that care coordination piece for physicians is taking a lot of time and energy. - HCW, \#26

We're definitely looking at caps and what we can reasonably do. Once we hit those caps it would just be wait-lists, and I mean it's all we can do. - FAO staff, \#33

Usually I have to take my kids with me 'cause it takes all of their bands, plus mine [to get the food bome from the food bank without a car]. But then it's bus fare for all of them, too." — patient, \#2

I think a challenge for people getting in bere is transportation. Or when we've tried to call the numbers they give us, they're disconnected or no longer in service." —FAO staff, \#35

[Many people] are just scared that they will affect applying for their citizenship or residence. FAO staff, \#31 
Table 2. Continued

\begin{tabular}{|c|c|c|}
\hline Themes & Stakeholder Perspectives* & Illustrative Quotations \\
\hline \multicolumn{3}{|c|}{ Findings on Closing the Loop } \\
\hline $\begin{array}{c}\text { Differing perspectives on } \\
\text { value and acceptability }\end{array}$ & $\begin{array}{l}\text { Patients: Generally recognize benefits but } \\
\text { request for permission a necessity and strong } \\
\text { privacy concerns among a minority of } \\
\text { respondents } \\
\text { HCWs: Strong positive view of benefits } \\
\text { FAO staff: Recognize potential benefits but } \\
\text { concern for client privacy }\end{array}$ & $\begin{array}{l}\text { I don't guess it would bother me. . .but you know, I think } \\
\text { that we need to know that they're doing that. . .sign a } \\
\text { paper or something. -patient, \#14 } \\
\text { I really don't want anybody to know that I'm on } \\
\text { [SNAP]. It's really nobody's business. . I'm not proud } \\
\text { of it. - patient, \#7 } \\
\text { I think that closing the referral is great. Then you know } \\
\text { what you're saying is belping or not. -HCW, \#21 } \\
\text { I think it would be belpful, but I don't know if [our } \\
\text { clients] would. I feel like some people might be judged } \\
\text { if they shared that information. By the providers. - } \\
\text { FAO staff, \#35 }\end{array}$ \\
\hline $\begin{array}{l}\text { Logistics and } \\
\text { implementation }\end{array}$ & $\begin{array}{l}\text { Patients: Concern about data security } \\
\text { HCWs: Importance of integration into existing } \\
\text { data systems and workflows } \\
\text { FAO staff: Concerns about time, cost, and } \\
\text { regulations }\end{array}$ & $\begin{array}{l}\text { I think the only thing I get nervous about is just the fact } \\
\text { that everything's being hacked lately. - patient, \#2 } \\
\text { We need to put it into our EMR, or just think about } \\
\text { where [the information] would go, and how would } \\
\text { that be done. - HCW, \# } 24 \\
\text { We're overstretched as it is, and adding like another } \\
\text { piece of data entry onto it, would be something that } \\
\text { we'd have to really look at to make sure that it was } \\
\text { wortbwhile for us to kind of do that extra work. - } \\
\text { FAO staff, \#32 } \\
\text { There could be the confirmation. . that the referral's } \\
\text { been received. We just can't confirm if [the person is] } \\
\text { eligible for the program or not due to federal privacy } \\
\text { regulations. - FAO staff, \#36 }\end{array}$ \\
\hline
\end{tabular}

HCWs, health care workers; FAO, food assistance organizations; EMR, electronic medical record; CPS, child protective services. *If a stakeholder group is not included for a theme, it indicates that particular theme did not emerge among that stakeholder group. ${ }^{\dagger}$ Numbers indicate specific interview participant (patients numbered 1-20, HCW numbered 21-30, FAO staff numbered 31-42).

given grant funding, volunteer staffing, and space limitations. For programs like WIC and SNAP, the concern was the work required to process more applications, particularly if there were incomplete applications or people were not actually interested in or eligible for the services. Similar to patients, they identified other barriers that prohibit connecting people with food resources, including fear of consequences such as loss of potential citizenship due to the public charge ground of inadmissibility rule $^{33}$ or CPS involvement.

\section{Survey Results}

In response to the question about helpfulness of data sharing for referrals, $72 \%$ of patients, $84 \%$ of HCWs, and only $43 \%$ of FAO staff thought this step was "very helpful"; $36 \%$ of patients thought people would be "very comfortable" (about the

Figure 2. Survey responses across stakeholder groups. Abbreviations: HCWs, health care workers; FAO, food assistance organizations.

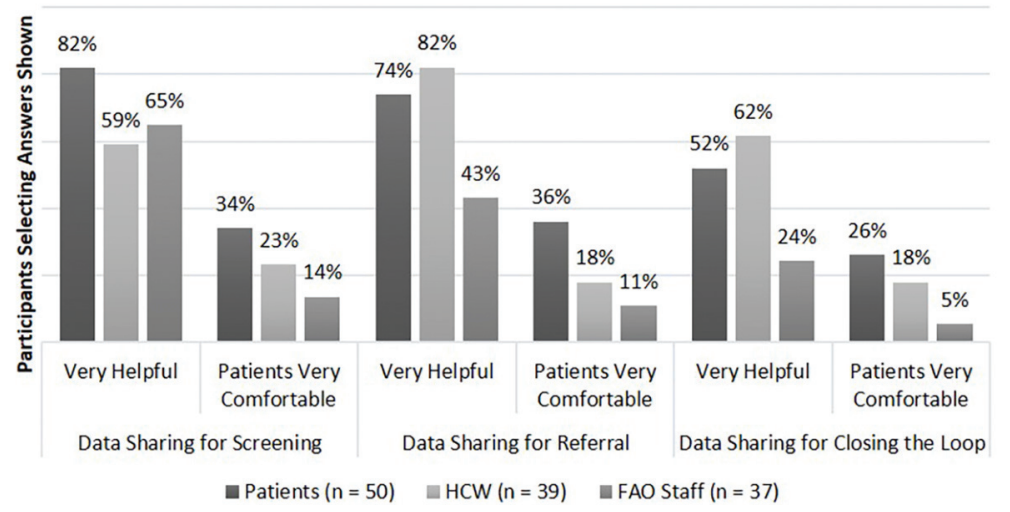


same as for comfort with screening), but only $11 \%$ of FAO staff and $18 \%$ of HCWs thought patients would be very comfortable with this step (see Figure 2).

\section{Closing the Loop \\ Qualitative Themes}

Perspectives differed more across groups for this step, with patients and FAO staff indicating greater privacy concerns and HCWs emphasizing its importance.

\section{Patients}

Most respondents said that they would be okay with this information sharing, but that they would want to be asked for permission. However, a few stated unequivocally that they would not want this information shared with their medical provider, as they felt receiving services was sensitive information. Respondents suggested that there could be shame around such information being shared due to the stigma around use of certain programs. Concerns about data security were also mentioned, specifically that data systems are vulnerable to hackers.

\section{HCWs}

This group was most adamant that this step is crucial for understanding patient circumstances. Care managers thought it would increase efficiency if they were able to easily receive information from FAOs regarding patients' receipt of services, noting that they often get no feedback after making a referral. They emphasized that the information would need to be easily obtainable, suggesting it automatically be put in patient charts through the electronic health record.

\section{FAO Staff}

Program staff were enthusiastic about greater collaboration with practices but emphasized that they were very protective of privacy. In general, they felt hesitant about data sharing, although some indicated that it would be acceptable if they had permission from the patient. Another concern was time required and cost to use a data-sharing system, especially for organizations that relied primarily on volunteers for staffing or limited budgets. Finally, several program staff indicated that data sharing was not something they could control and that any decisions about data sharing would happen at a higher leadership level.

\section{Survey Results}

Fifty-two percent of patients and 24\% of FAO staff thought this final step in the process was "very helpful," compared with $62 \%$ of HCWs. Regarding patient comfort, only $5 \%$ of FAO staff thought patients would be "very comfortable" with closing the loop, compared with $26 \%$ of patients and $18 \%$ of HCWs.

\section{Discussion}

Broadly, people from all stakeholder groups believed that FI was important to address in health care settings and that screening for FI and connecting patients with resources was valuable. However, there were differences in comfort with and perception of the importance of data sharing between medical practices and FAOs. FAO staff were the most concerned about client privacy related to information sharing. In addition, FAO staff are required to capture and report data for grants and federal or state programs using specific systems, which makes sharing additional data through different systems challenging. HCWs were unsure of how HIPAA regulations apply to sharing of SDOH-related information, an issue that is not entirely clear despite recent efforts to integrate screening and referral into practice. ${ }^{34,35}$ In addition, some patients had concerns with each step of the process, primarily related to privacy and the potential for shame or stigma around either experiencing FI or receiving services. These findings concur with and build on previous research documenting concerns among some patients related to privacy and stigma around FI and other SDOH needs. ${ }^{36-39}$ They add new insights from the perspective of FAO staff, whose views are often not considered when developing FI referral systems. ${ }^{40}$ They also provide insight into perspectives of people living in a rural and small-town setting.

These findings may have implications for the use of referral systems and how they are implemented. First, it was important to all stakeholders that the work required to screen, refer, and close the loop lead to reduction in FI. Burnout and information overload already exist in primary care such that some experts feel that adding another process like screening for $\mathrm{SDOH}$ needs is not feasible or worth 
the effort. ${ }^{41,42}$ Primary care providers and staff wanted to know they could do something with information on patients' FI, because screening itself is another task in an already taxed system. Similarly, FAO staff expressed concerns about their ability to participate in a referral system due to resource limitations and workload. For effective systems to be developed and adopted, this added workload should be addressed. ${ }^{43}$ In addition, as has been found elsewhere, patients reported that access to information or referral is not the only or primary barrier to accessing resources. ${ }^{44}$ This points to the need for multilevel structural and policy change, in addition to efforts to address FI within primary care settings. ${ }^{45}$

Second, we learned that personal relationships with clinic staff may make screening and referral more comfortable for patients, leading to more honest responses, but face-to-face screening is challenging for practices given time constraints. While the literature is mixed on whether people are more honest when responding to in-person questions compared with computer or article questionnaires, ${ }^{46-48}$ there is strong evidence that patients are more comfortable discussing sensitive topics when there is a close relationship with staff. ${ }^{49,50}$ This has implications for workflow, as many practices currently use patient-completed article screening forms. Finally, this supports recommendations for approaching screening for SDOH from a teambased and patient centered approach. ${ }^{51}$

A limitation of this work is that these data represent conveniently sampled stakeholders in 1 area of western Colorado and may not represent the views of people in other geographic areas or contextual circumstances. In addition, the work was conducted both with patients who have experienced screening for FI and those who have not, so some of their responses may be more speculative than a description of their personal experience (ie, possible selection or recall bias). ${ }^{52}$

\section{Conclusions}

Our findings provide multiple stakeholder perspectives for health care settings that are currently implementing or seeking to implement screening and referral for needs related to SDOH. In particular, our findings provide new insights about sharing data about FI between primary care settings and FAOs. While all stakeholders see some benefit to these processes, concerns still exist and differ across stakeholder groups. FAO staff in particular have concerns about privacy, ability to share information, and whether people experiencing FI will truly benefit. Patients and FAO staff were generally more comfortable with screening and referral and less comfortable with closing the loop. In contrast, HCWs felt strongly that closing the loop is crucial, and if systems do not feed information back to practices, there is a potential that screening and referral could be jettisoned due to other pressing clinical tasks. Critical components of addressing FI in primary care settings include robust procedures for obtaining permission for data sharing at each step of the process, communicating with patients about reasons for data sharing, easing the administrative burden of data sharing for HCW and FAO staff, and reassuring FAO staff that data will be treated with confidentiality and respect.

We are grateful to all of our community partners in Mesa County, Colorado, who participated in this work, as well as to Elizabeth Staton for technical writing support.

To see this article online, please go to: http://jabfm.org/content/ 35/1/85.full.

\section{References}

1. Institute of Medicine. Capturing social and behavioral domains and measures in electronic health records: phase 2. Washington (DC): National Academies Press; 2014.

2. Fraze TK, Brewster AL, Lewis VA, Beidler LB, Murray GF, Colla CH. Prevalence of screening for food insecurity, housing instability, utility needs, transportation needs, and interpersonal violence by US physician practices and hospitals. JAMA Netw Open 2019;2:e1911514-e1911514.

3. Andermann A. Screening for social determinants of health in clinical care: moving from the margins to the mainstream. Public Health Rev 2018;39:19.

4. Page-Reeves J, Moffett ML, Steimel L, Smith DT, The evolution of an innovative community-engaged health navigator program to address social determinants of health. Prog Community Health Partnersh 2016;10:603-10.

5. Smith S, Malinak D, Chang J, et al. Implementation of a food insecurity screening and referral program in student-run free clinics in San Diego, California. Prev Med Rep 2017;5:134-9.

6. Hager ER, Quigg AM, Black MM, et al. Development and validity of a 2 -item screen to identify families at risk for food insecurity. Pediatrics 2010;126:e26-e32.

7. Council on Community Pediatrics, Committee on Nutrition. Promoting food security for all children. Pediatrics 2015;136:e1431-e1438. 
8. US Department of Agriculture Economic Research Service [Internet]. Definitions of food security; 2020 [cited 2020 Dec 16]. Available from: http:// www.ers.usda.gov/topics/food-nutrition-assistance/ food-security-in-the-us/definitions-of-food-security. aspx.

9. Feeding America [Internet]. Facts about poverty and hunger in America; 2020 [cited 2021 Jan 26]. Available from: https://www.feedingamerica.org/ hunger-in-america/facts.

10. Schanzenbach D, Pitts A. How much has food insecurity risen? Evidence from the census household pulse survey. Institute for Policy Research Rapid Research Report; 2020.

11. Cullen D, Abel D, Attridge M, Fein JA. Exploring the gap: food insecurity and resource engagement. Acad Pediatr 2021;21:440-5.

12. Garg A, Marino M, Vikani AR, Solomon BS. Addressing families' unmet social needs within pediatric primary care: the health leads model. Clin Pediatr (Phila) 2012;51:1191-3.

13. Redding S, Conrey E, Porter K, Paulson J, Hughes $\mathrm{K}$, Redding M. Pathways community care coordination in low birth weight prevention. Matern Child Health J 2015;19:643-50.

14. Gottlieb L, Hessler D, Long D, Amaya A, Adler N. A randomized trial on screening for social determinants of health: the iScreen study. Pediatrics 2014; 134:e1611-e1618.

15. Hassan A, Scherer EA, Pikcilingis A, et al. Improving social determinants of health: effectiveness of a web-based intervention. Am J Prev Med 2015;49:822-31.

16. Peek ME, Odoms-Young A, Quinn MT, GorawaraBhat R, Wilson SC, Chin MH. Race and shared decision-making: perspectives of African-Americans with diabetes. Soc Sci Med 2010;71:1-9.

17. James R, Tsosie R, Sahota P, Kiana Group, , et al. Exploring pathways to trust: a tribal perspective on data sharing. Genet Med 2014;16:820-6.

18. Abdelhamid M, Gaia J, Sanders GL. Putting the focus back on the patient: how privacy concerns affect personal health information sharing intentions. J Med Internet Res 2017;19:e169.

19. Bansal G, Zahedi FM, Gefen D. The impact of personal dispositions on information sensitivity, privacy concern and trust in disclosing health information online. Decision Support Systems 2010;49: 138-50.

20. Barnidge E, Krupsky K, LaBarge G, Arthur J. Food insecurity screening in pediatric clinical settings: a caregivers' perspective. Matern Child Health J 2020;24:101-9.

21. Cullen D, Attridge M, Fein JA. Food for thought: a qualitative evaluation of caregiver preferences for food insecurity screening and resource referral. Acad Pediatr 2020;20:1157-62.
22. Rogers AJ, Hamity C, Sharp AL, Jackson AH, Schickedanz AB. Patients' attitudes and perceptions regarding social needs screening and navigation: multi-site survey in a large integrated health system. J Gen Intern Med 2020;35:1389-95.

23. Taylor LA, Byhoff E. Money moves the mare: the response of community-based organizations to health care's embrace of social determinants. Milbank Q 2021;99:171-208.

24. Creswell J. Educational research: planning, conducting, and evaluating quantitative and qualitative research. 2nd ed. Ann Arbor (MI): Merrill; 2005.

25. Tong A, Sainsbury P, Craig J. Consolidated criteria for reporting qualitative research (COREQ): a 32 item checklist for interviews and focus groups. Int $\mathrm{J}$ Qual Health Care 2007;19:349-57.

26. United States Census Bureau [Internet]. QuickFacts Mesa County, Colorado; 2019 [cited 2020 Dec 21]. Available from: https://www.census.gov/quickfacts/ fact/table/CO,mesacountycolorado/PST045219.

27. Feeding America [Internet]. Food insecurity in Mesa County; 2018 [cited 2021 Feb 24]. Available from: http://map.feedingamerica.org/county/2018/ overall/colorado/county/mesa.

28. Taylor B, Henshall C, Kenyon S, Litchfield I, Greenfield S. Can rapid approaches to qualitative analysis deliver timely, valid findings to clinical leaders? A mixed methods study comparing rapid and thematic analysis. BMJ Open 2018;8: e019993.

29. Gale RC, Wu J, Erhardt T, et al. Comparison of rapid vs in-depth qualitative analytic methods from a process evaluation of academic detailing in the Veterans Health Administration. Implement Sci 2019;14:11.

30. Palinkas LA, Zatzick D. Rapid assessment procedure informed clinical ethnography (RAPICE) in pragmatic clinical trials of mental health services implementation: methods and applied case study. Adm Policy Ment Health 2019;46:255-70.

31. Palinkas LA, Mendon SJ, Hamilton AB. Innovations in mixed methods evaluations. Annu Rev Public Health 2019;40:423-42.

32. Saldana JC. An introduction to codes and coding. In: The coding manual for qualitative researchers. Los Angeles: Sage; 2016.

33. Services USCaI [Internet]. Final rules on public charge ground of inadmissibility; 2020 [cited 2021 Jan 26]. Available from: https://www.uscis.gov/ archive/final-rule-on-public-charge-ground-ofinadmissibility.

34. Bean A, Jaynes J, Sexton T. Determining the shared population between service providers: How Tulsa is preserving privacy and sharing data for social good. Asemio; 2019.

35. Aagaard J, Hethcoat G. The social determinants of health: the next HIPAA frontier. 27th National HIPAA Summit; 2018. 
36. Gaines-Turner T, Simmons JC, Chilton M. Recommendations from SNAP participants to improve wages and end stigma. Am J Public Health 2019;109:1664-7.

37. Garthwaite K. Stigma, shame and "people like us": an ethnographic study of foodbank use in the UK. J Poverty Soc Justice 2016;24:277-89.

38. Pak T-Y. Welfare stigma as a risk factor for major depressive disorder: evidence from the Supplemental Nutrition Assistance Program. J Affective Disorders 2020;260:53-60.

39. El Zein A, Mathews AE, House L, Shelnutt KP. Why are hungry college students not seeking help? Predictors of and barriers to using an on-campus food pantry. Nutrients 2018;10:1163.

40. Runkle NK, Nelson DA. The silence of food insecurity: disconnections between primary care and community organizations. J Patient Cent Res Rev 2021;8:31-8.

41. Singh H, Spitzmueller C, Petersen NJ, Sawhney MK, Sittig DF. Information overload and missed test results in electronic health record-based settings. JAMA Intern Med 2013;173:702-4.

42. Solberg LI. Theory vs practice: should primary care practice take on social determinants of health now? No. Ann Fam Med 2016;14:102-3.

43. Gottlieb L, Ackerman S, Wing H, Manchanda R. Understanding Medicaid managed care investments in members' social determinants of health. Popul Health Manag 2017;20:302-8.

44. McCarthy ML, Zheng Z, Wilder ME, et al. Latent class analysis to represent social determinant of health risk groups in the Medicaid cohort of the District of Columbia. Medical Care 2021;59:251-8.
45. DeWit EL, Meissen-Sebelius EM, Shook RP, et al. Beyond clinical food prescriptions and mobile markets: parent views on the role of a healthcare institution in increasing healthy eating in food insecure families. Nutr J 2020;19:1-12.

46. Fincher D, VanderEnde K, Colbert K, Houry D, Smith LS, Yount KM. Effect of face-to-face interview versus computer-assisted self-interview on disclosure of intimate partner violence among African American women in WIC clinics. J Interpers Violence 2015;30:818-38.

47. Chang L, Krosnick JA. Comparing oral interviewing with self-administered computerized questionnaires: an experiment. Public Opinion Quarterly 2010;74:154-67.

48. Bowling A. Mode of questionnaire administration can have serious effects on data quality. J Public Health (Oxf) 2005;27:281-91.

49. Capell B, Tzafrir SS, Enosh G, Dolan SL. Explaining sexual minorities' disclosure: the role of trust embedded in organizational practices. Organization Studies 2018;39:947-73.

50. Ganzini L, Denneson LM, Press N, et al. Trust is the basis for effective suicide risk screening and assessment in veterans. J Gen Intern Med 2013;28:1215-21.

51. Schoenthaler A, Hassan I, Fiscella K. The time is now: fostering relationship-centered discussions about patients' social determinants of health. Patient Educ Couns 2019;102:810-4.

52. Pannucci CJ, Wilkins EG. Identifying and avoiding bias in research. Plast Reconstr Surg 2010; 126:619-25. 